\title{
A Comparative Study Of Initial Stage Climate Responsive Design Guideline In Residential Settings Based On The Thermal Comfort Models Of Climate Consultant For Five Regions Of Pakistan
}

\author{
Asma Khalid ${ }^{1}$
}

\begin{abstract}
:
Thermal comfort can be achieved by analyzing the dynamic behavior of the climate and considering all the architectural possibilities, as defined by the Climate Consultant for all five climate zones of Pakistan. The Climate Consultant software, lists 20 design guidelines (DGs) based on the design strategies and the criteria defined for each model. The comparative analysis of these guidelines helps to outline commonalities and differences in four Human Thermal Comfort models (HTCMs). The variety of guidelines achieved from these four thermal comfort models give the best possible combination of design guidelines for all five regions of Pakistan. The ASHRAE adaptive comfort model proposes a totally different set of guidelines, most suitable for naturally ventilated residential buildings. The California code, ASHRAE 55, and ASHRAE 2005 proposes a set of design guidelines with the largest possible similarity, suitable for all building types. The paper concludes similar climate responsive passive design principles using climate consultant software for the five climate regions of Pakistan.
\end{abstract}

Keywords: Climate Consultant, Climate responsive buildings, Design guidelines, Human thermal comfort model, Passive design

\section{Introduction}

Recent scientific contributions about climate change and its impact on human life is alarming the people to the limit of 1.5 or 2 degree Celsius (Parmesan and Yohe 2003, Erickson and Tempest 2014, Millar, Fuglestvedt et al. 2017). The unsustainable choices of using earth resources, has resulted in increased carbon emissions, and other socio-economic issues. International policy makers on climate change are referring to the pre-industrial $\mathrm{CO}_{2}$ for habitat as baseline model (Holdgate 1987). Buildings are responsible for $32 \%$ of global energy use and 19\% greenhouses gases emissions, contributing to the global temperature rise (Omer 2008). The industrialized building materials, and construction technologies are putting serious harm to the environment. The increased use of heating and cooling devices, becoming the necessity of modern age to meet the comfort condition and are considered as part of high standard living. It had badly affected the indoor and outdoor air quality and thermal comfort conditions. The architects and planners in their specific realm are finding standardised solution to the environmental and health concerns. The criteria of EU standards and IPCC demand the thermal comfort solution of building using passive design, material and techniques. The zero energy building and low carbon foot print of recent construction can help to meet the current building construction, environmental and health standards. One of the world

| ${ }^{1}$ Lecturer, Department of Product and Industrial design, University of Engineering and Technology, Lahore, Pakistan 
wide mitigation strategies is to design codes and standards for the buildings. The standardized approach is combined with the simulation technologies are helping designers to mapping the initial stage design guidelines for more climate friendly building design.

\section{Situation of Residential Sector of Pakistan}

Like many other developing countries, Pakistan is also facing a big challenge of energy and environmental crisis. The international practices of developing an effectively applicable building standard is the need of today and of the future generation in order to meet the challenges of sustainbilty. The commercial codes have catalzed the stakeholders to improve the energy efficient practices for buildings in Pakistan. Building contributes the major component of the residential sector, consuming more than $40 \%$ of the energy and $75 \%$ of the electricity produced in the world. Residential buildings in Pakistan lack the energy conservation strategies, and practices. The residential sector being higgest end consumers of resources can also be optimized by following energy efficient practices.

In addition to that, population growth, urbanization and industrialization have adversely affected the housing situation in Pakistan. Over 40 million additional people are expected to live in the towns and cities of Pakistan by 2025 (UN-Habitat 2010). In Pakistan, the building sector consumes about $35 \%$ of the national electricity with domestic housing taking 85\% of this slice (Enercon 1994). The Residential sector of Pakistan consumes about 33,704 GWh of electricity (ADB 2009). In the last two decades, the household electricity consumption has grown robustly with an increase of 10.4\% (HDIP 2013).

\section{Residential Architecture}

In Pakistan, architecture is enriched with the traditional and vernacular housing. These examples of the urban morphological character make it distinguishable from the other arenas. Their design principle is based on local, indigenous materials and techniques. However, modernization is blended with traditional concept in a way that it has lost with the climatic features. The building topographies are not designed with the consideration of the climate and the environment. The catastrophic effect of heat integration has resulted in the urban heat island effect.

The urban communities in Pakistan are far too dependent on the electricity to meet the cooling energy requirements and overcome the discomfort caused by the severe weather conditions. The improved awareness amongst the building stakeholders have led them to opt for the traditional passive cooling strategies, particular to the regional characteristics. The foremost things that are needed in the initial design stage of a particular house are the climate background and common effectively applicable deign strategies and guidelines. It will help the designer propose climate responsive designs to achieve the thermal comfort in a particular situation. The lack of residential standards has also led to the poor design of urban societies. In order to design the climate responsive buildings, climate studies provide the foundation for these passive design techniques. 


\section{Climatic Studies in Pakistan}

Pakistan has a very diverse climate at macro and micro scale. The outdoor climatic conditions and their variability affect the indoor design conditions. (Nicol and Raja 1997) Various climatic studies have been presented because of the existence of reasonably good network observatories recording the basic climate parameters of rainfall and temperature. The basic climatic parameters of temperature and precipitation provide climate similarity in all previously conducted climatic studies. The studies (Shamshad 1988, Khan 1991, Raja, Dougar et al. 1996) propose 8 zones, 11 zones and 16 zones climate division for Pakistan respectively. Pakistan is divided into five major climatic regions. (Nicol, Raja et al. 1999) The Enercon Pakistan uses this five zone classification for developing Building Energy Code of Pakistan (BECP), indoor temperature standards and for all other energy consumption studies of buildings. (Nicol, Raja et al. 1999) has selected five cities with each representative of a specific zone, Karachi as tropical coast land (Zone I), Multan as Subtropical continental Lowlands arid (Zone II), Quetta as Subtropical continental, Highlands semi-arid $\backslash$ sub-humid (Zone III), Lahore as Subtropical continental, low lands sub-humid (Zone IV) and Gilgit Baltistan as Subtropical continental, highlands humid (Zone V).

\section{Climate Responsive Building Design Guidelines}

Climate responsive building is a low tech passive design based building that responds to different climate conditions, weather related attributes and diurnal shifts. (Lehmann 2011) The purpose of a climate responsive building is to maximize the indoor comfort with minimum energy input (Krishan 2001). Climate responsive and passive design are interchangeably used in architecture for achieving thermal comfort (ÇERÇİ 2014). Both deal with climate and human thermal response. (Humphreys 1975, Nicol and Roaf 1996, Nicol, Raja et al. 1999, Nicol and Humphreys 2002, Nicol 2004) studies are based on the thermal comfort field studies for improving the comfort conditions in naturally ventilated buildings. But the recent application of worldwide thermal comfort studies has led to specific design guidelines based on simulation analysis. Many studies like (Givoni 1992, Givoni 1998, Olgyay 2015) outline climate responsive design based on bio climate approach of a building. The Climate Consultant is also an effectively applicable tool for the initial stage design guidelines based on the climate analysis.

\section{Comfort models of Climate Consultant}

Comfort model are defined by the human thermal response to their environmental conditions and surroundings. The climate consultant software provides the provision of using four thermal comfort models of California code, ASHRAE 55, 2005 and adaptive model. The first three models consider the sizing of cooling and heating systems using environmental parameter. The adaptive model is more suitable for naturally ventilated buildings, where occupants can open and close windows for their changing response from the outdoor condition to achieve indoor comfort. the following parameters have been defined for the criteria setting of extracting design guidelines. 


\section{Objectives}

The purpose of the study is to provide the climate responsive design guidelines for five representative cities of Pakistan. These guidelines are helpful for the initial stage design of a house.

\section{Methodology}

This study is based on the comparative analysis of four human thermal comfort models (HTCMs) available in Climate Consultant. In each of the four options, for all climate regions (Karachi, Multan, Lahore, Quetta and Gilgit), a sequence of 20 design guidelines is available. These guidelines are specific to the climate of each region, therefore each guideline must be considered in a defined order, starting with the first as most important and so on (Milne 2014). The comparative analysis of these guidelines among the four comfort models will give the variety of passive design techniques. These passive design techniques may serve well as climate responsive design approaches for each region of a climate zone. It can also be helpful in defining similarities among the design guidelines using all options for all five regions of Pakistan.

The

, 2, 3, 4, and 5 give a distribution of design guidelines using four comfort models for Karachi, Multan, Lahore, Quetta and Gilgit regions.

\subsection{Comparative analysis of design guidelines for Karachi}

Following results have been drawn for Karachi from the comparative analysis of HTCMs ( ) .

1. Combining all the four options provided by the Climate Consultant, there are a total of 38 design guidelines (DGs) which can be considered for designing the climate responsive buildings in Karachi.

2. Amongst 38 DGs, only 7 DGs are common in all the four options.

3. There are 5 DGs which are similar in any 3 options. The California energy code (CEC), ASHRAE 55 and the ASHRAE 2005 four options in similar.

4. There are 12 DGs that are similar in any two combinations of HTCMs. So, CEC and ASHRAE Standards 55 have the largest similarities compared to other options of HTCMs.

It has also been found that ASHRAE adaptive comfort (option 4) has the largest dissimilarities for Karachi. Amongst the 14 dissimilar DGs found in all HTCMs, there are 7 dissimilar DGs using option 4. The ASHRAE 55 and ASHRAE 2005 have 3 dissimilar DGs in each option, whereas CEC has just 1 DG dissimilarity in all four options. 
Table 1: Distribution of design guidelines for Karachi

\begin{tabular}{|l|l|l|l|l|l|l|l|l|l|l|l|l|l|l|}
\hline No & Design guidelines & \multicolumn{10}{|l|}{ Karachi } \\
\hline 1 & Similar & 35 & 33 & 56 & 42 & 17 & 32 & 37 & & & & & & \\
\hline 2 & Similar in 3 & 47 & 59 & 38 & 43 & 46 & & & & & & & & \\
\hline 3 & Similar in 2 & 65 & 25 & 27 & 66 & 30 & 61 & 26 & 57 & 18 & 60 & 53 & 36 & \\
\hline 4 & Dissimilar & 55 & 54 & 62 & 58 & 39 & 49 & 34 & 19 & 20 & 68 & 24 & 40 & 45 \\
\hline
\end{tabular}

\subsection{Comparative analysis of design guidelines for Multan}

\begin{tabular}{|c|c|c|c|c|c|c|c|c|c|c|c|c|}
\hline \multirow{2}{*}{$\begin{array}{l}\mathbf{0} \\
1 \\
\end{array}$} & \multirow{2}{*}{$\begin{array}{l}\text { Design guidelines } \\
\text { Similar }\end{array}$} & \multicolumn{11}{|c|}{ Multan } \\
\hline & & 37 & 32 & 42 & 35 & 17 & 33 & 56 & & & & \\
\hline 2 & Similar in 3 & 59 & 20 & 66 & 38 & 43 & 46 & 40 & 19 & 26 & & \\
\hline 3 & Similar in 2 & 65 & 45 & 39 & 24 & 61 & 18 & 47 & & & & \\
\hline 4 & Dissimilar & 60 & 34 & 36 & 49 & 58 & 62 & 53 & 54 & 55 & 25 & 27 \\
\hline
\end{tabular}

concludes the following discussion for the climate of Multan using all four options of HTCMs.

1. There are total 34 DG's identified using all four comfort models for the climate of Multan.

2. Similar to Karachi, there are 7 DG's common in all four options and can possibly be considered best while designing residences in Multan.

3. There are 9 DG's similar in the first 3 options of HTCMs. So, the CEC, ASHRAE 55 and ASHRAE 2005 have all the options similar in the case of Multan.

4. Additionally, there are 7 DG's found common using any two options of the available HTCMs. There are 2 DG's similar in any two combinations (option 1, 4 and option 2, 3). 5. The option 4, using adaptive thermal comfort gives 11 DG's. They are still considerable because of their application in naturally ventilated buildings.

Table 2: Distribution of design guidelines for Multan

\begin{tabular}{|l|l|l|l|l|l|l|l|l|l|l|l|l|}
\hline No & Design guidelines & \multicolumn{8}{|l|}{ Multan } \\
\hline 1 & Similar & 37 & 32 & 42 & 35 & 17 & 33 & 56 & & & & \\
\hline 2 & Similar in 3 & 59 & 20 & 66 & 38 & 43 & 46 & 40 & 19 & 26 & & \\
\hline 3 & Similar in 2 & 65 & 45 & 39 & 24 & 61 & 18 & 47 & & & & \\
\hline 4 & Dissimilar & 60 & 34 & 36 & 49 & 58 & 62 & 53 & 54 & 55 & 25 & 27 \\
\hline
\end{tabular}




\subsection{Comparative analysis of design guidelines for Lahore}

Following results have been drawn for the climate of Lahore through the comparative analysis of DG's in all four options of HTCMs. (Table )

1. Amongst the 34 DG's found for the climate of Lahore, there are 7 DG's similar in all four options of HTCMs.

2. CEC, ASHRAE 55, and ASHRAE 2005 have the largest similarities to the climate of Lahore and there are 11 DG's similar using these three HTCMs.

3. There are 14 DG's found dissimilar in all four options and the adaptive thermal comfort model gives 12 DG's from this total.

Table 3: Distribution of design guidelines for Lahore

\begin{tabular}{|c|c|c|c|c|c|c|c|c|c|c|c|c|c|c|c|}
\hline $\begin{array}{l}\mathrm{N} \\
\mathrm{O}\end{array}$ & Design guidelines & & & & & & & & & & & & & & \\
\hline 1 & Similar & $\begin{array}{l}3 \\
7\end{array}$ & $\begin{array}{l}3 \\
5\end{array}$ & $\begin{array}{l}3 \\
2\end{array}$ & $\begin{array}{l}4 \\
2\end{array}$ & $\begin{array}{l}1 \\
7\end{array}$ & $\begin{array}{l}5 \\
6\end{array}$ & $\begin{array}{l}3 \\
3\end{array}$ & & & & & & & \\
\hline 2 & Similar in 3 & $\begin{array}{l}2 \\
0\end{array}$ & $\begin{array}{l}6 \\
6\end{array}$ & $\begin{array}{l}5 \\
9\end{array}$ & $\begin{array}{l}3 \\
8\end{array}$ & $\begin{array}{l}6 \\
1\end{array}$ & $\begin{array}{l}4 \\
3\end{array}$ & $\begin{array}{l}1 \\
9\end{array}$ & $\begin{array}{l}2 \\
6\end{array}$ & $\begin{array}{l}4 \\
5\end{array}$ & $\begin{array}{l}4 \\
6\end{array}$ & $\begin{array}{l}1 \\
8\end{array}$ & $\begin{array}{l}4 \\
7\end{array}$ & & \\
\hline 3 & Similar in 2 & $\begin{array}{l}4 \\
0\end{array}$ & & & & & & & & & & & & & \\
\hline 4 & Dissimilar & $\begin{array}{l}6 \\
0\end{array}$ & $\begin{array}{l}1 \\
1\end{array}$ & $\begin{array}{l}3 \\
4\end{array}$ & $\begin{array}{l}3 \\
6\end{array}$ & $\begin{array}{l}4 \\
9\end{array}$ & $\begin{array}{l}3 \\
9\end{array}$ & $\begin{array}{l}5 \\
8 \\
\end{array}$ & $\begin{array}{l}6 \\
2\end{array}$ & $\begin{array}{l}6 \\
5 \\
\end{array}$ & $\begin{array}{l}5 \\
3\end{array}$ & $\begin{array}{l}5 \\
4\end{array}$ & $\begin{array}{l}5 \\
5\end{array}$ & $\begin{array}{l}2 \\
5\end{array}$ & $\begin{array}{l}2 \\
7\end{array}$ \\
\hline
\end{tabular}

\subsection{Comparative analysis of design guidelines for Quetta}

The following conclusions have been drawn for the Quetta region using Table .

1. The software proposes 35 DG's for the Quetta region using all four options of HTCMs and gives only 4 similar DG's similar in all four options.

2. There are 13 DG's similar in any three HTCMs. Amongst them, option 1, 2 and 3 have the largest similarity with 11 DG's in common.

3. There are 7 similar DG's using any two options of HTCMs. There are three DG's similar in the California model and ASHRAE 2005. The other four DG's are common in ASHRAE 55 and the adaptive model.

4. Amongst 11 dissimilar DG's found in HTCMs, there are 10 DG's contributed by the ASHRAE adaptive model. The adaptive model has found the largest proportion of dissimilar DG's in all climate regions. This is mainly because of the nature and particularity of standards suitable for naturally ventilated buildings, where the occupants are provided with the flexibility of adapting themselves according to the situation.

Table 4: Distribution of design guidelines for Quetta

\begin{tabular}{|l|l|l|}
\hline No & Design guidelines & Quetta \\
\hline
\end{tabular}




\begin{tabular}{|l|l|l|l|l|l|l|l|l|l|l|l|l|l|l|}
1 & Similar & 37 & 42 & 47 & 35 & & & & & & & & & \\
\hline 2 & Similar in 3 & 50 & 29 & 60 & 61 & 19 & 20 & 11 & 43 & 54 & 3 & 32 & 31 & 14 \\
\hline 3 & Similar in 2 & 45 & 66 & 8 & 58 & 62 & 55 & 33 & & & & & & \\
\hline 4 & Dissimilar & 41 & 34 & 36 & 56 & 49 & 39 & 65 & 53 & 17 & 25 & 27 & & \\
\hline
\end{tabular}

\subsection{Comparative analysis of design guidelines for Gilgit Baltistan}

Climate Consultant proposes following conclusions for the Gilgit Baltistan as shown in Table.

1. It is the only region that proposes maximum dissimilarity amongst the DG's using all HTCMs. There are 21 DG's found dissimilar out of 41 DG's using all four options of HTCMs.

2. All dissimilar DG's belong to the adaptive model.

3. The California model, ASHRAE 55 and 2005 have the largest similarity and there are

19 DG's found common using option 1, 2 and 3.

4. Unfortunately, there is no DG similar for this case using all the four options.

5. There is only one design guideline (No: 28) found similar using option 2 and 3.

Table 5: Distribution of design guidelines for Gilgit

\begin{tabular}{|l|l|l|l|l|l|l|l|l|l|l|l|l|l|l|l|l|l|l|l|l|l|}
\hline $\begin{array}{l}\text { N } \\
\text { O }\end{array}$ & $\begin{array}{l}\text { Design } \\
\text { guidelines }\end{array}$ & \multicolumn{10}{|l|}{ Gilgit } \\
\hline 1 & Similar & & & & & & & & & & & & & & & & & & & & \\
\hline \\
2
\end{tabular}

\section{Discussion}

Figure 1 has been drawn through the comparative analysis of the design guidelines using HTCMs for five regions. 


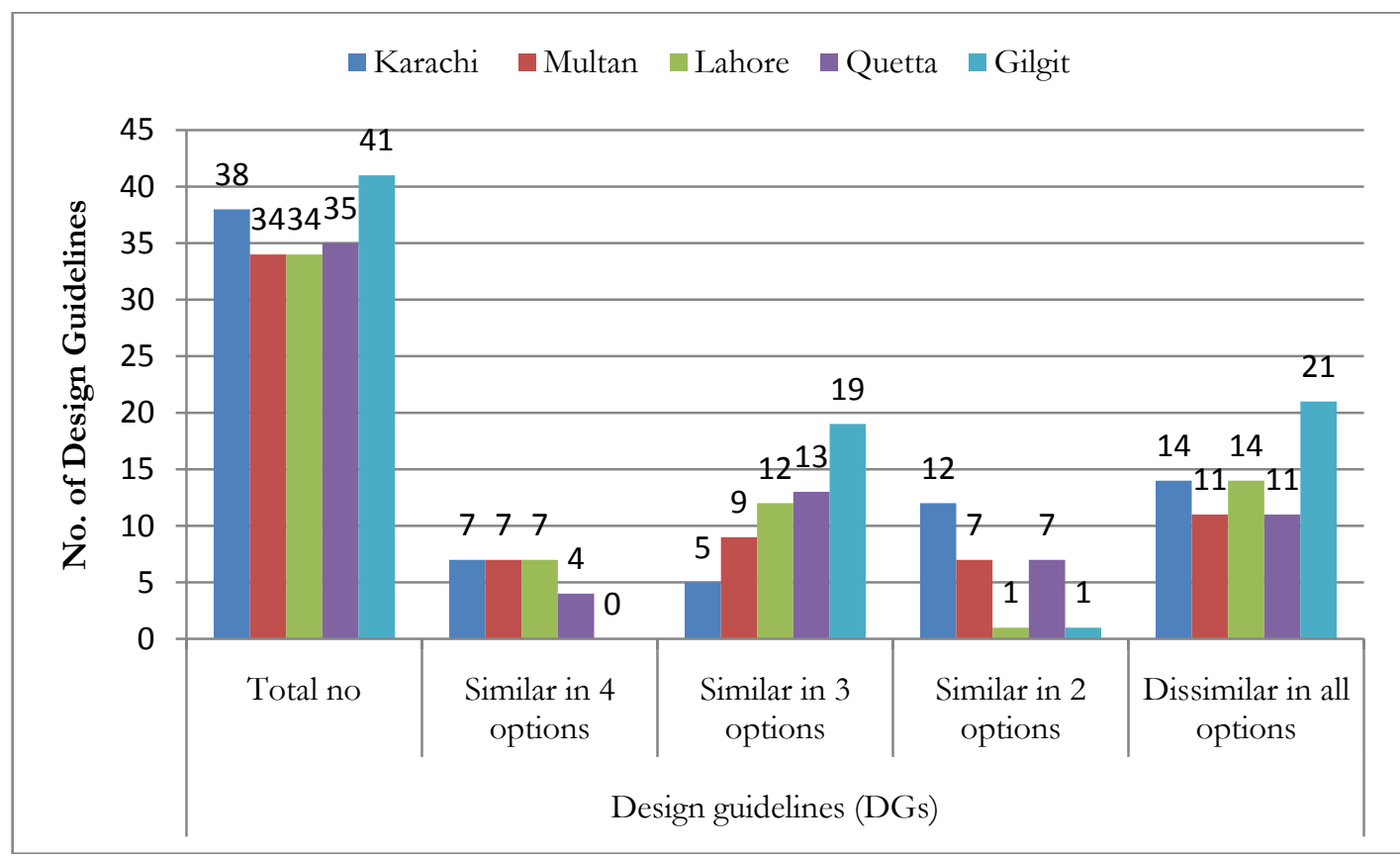

Figure 1: Comparative analysis of design guidelines for five regions using HTCMs

The design guidelines specified for all five regions achieved from climate consultant analysis are summarized in Annexure. These design guidelines are classified into seven categories on the basis of effectively applicable climate responsive passive principles. The Passive home principles are based on material, design features for the envelope, roof, windows, and landscape. The guidelines for the system are also included in Table 6 because of ASHRAE 55, 2005 and CEC.

Table 6: Similarities in design guidelines for five climatic regions of Pakistan

\begin{tabular}{|l|l|l|}
\hline Number & Category & Design guideline \\
\hline 1 & Materials & Tiles, slate, stone-faced fireplace \\
\hline 4 & & Super insulation \\
\hline 24 & & High mass interior surfaces \\
\hline 26 & & Radiant barrier \\
\hline 41 & & Exterior insulation \\
\hline 60 & & High mass construction \\
\hline & & \\
\hline 2 & Design & Exterior or interior insulation for basement 18 "below frost line \\
\hline 9,18 & & Minimize A/V (surface to volume ratio) \\
\hline 14 & & Side facing garages or storage areas \\
\hline 24,40 & & High mass interior surfaces \\
\hline 27 & & $\begin{array}{l}\text { Lower ground design to minimize dampness and maximize } \\
\text { natural ventilation }\end{array}$ \\
\hline 31 & & Solar oriented floor plan \\
\hline 33 & & Long, narrow floor plans \\
\hline $34, \quad 35$, & & Natural ventilation \\
\hline
\end{tabular}




\begin{tabular}{|c|c|c|}
\hline 36,47 & & \\
\hline 39 & & Fan forced ventilation \\
\hline 49 & & Stack ventilation \\
\hline 11,28 & Windows & Internal heat gain \\
\hline 19 & & South facing windows with overhangs \\
\hline 20,30 & & High performance glazing for all orientations \\
\hline 23 & & Small well-insulated skylights \\
\hline 32 & & Minimize west glazing \\
\hline 57 & & North orient glass, with vertical fins \\
\hline 7 & Element & Vestibules \\
\hline 8 & & Seasonal sun rooms, enclosed patios, courtyards, verandahs \\
\hline 12,37 & & Insulating blinds, heavy draperies, operable window shutters \\
\hline 29 & & Spray like fountain, misters, wet payments, cooling towers \\
\hline 56 & & Screened porches \\
\hline 16 & Landscape & Conifer or deciduous tree plantation 450 \\
\hline 17 & & West facing native plants (bushes, trees, ivy-covered walls) \\
\hline 43 & Roof & Cool roofs \\
\hline 45 & & Light colored flat roof \\
\hline 13,25 & & Steep pitched roof, with a vented attic \\
\hline 55 & & Low pitched roofs \\
\hline 15 & System & High Efficiency furnace \\
\hline 22 & & Heat or Energy Recovery Ventilator \\
\hline 42 & & Ceiling fan \\
\hline 46 & & High Efficiency air conditioner or heat pump \\
\hline 50 & & Evaporative Cooler \\
\hline 60 & & Earth sheltering, occupied basements, earth tubes \\
\hline
\end{tabular}

This study uses the same numeric number as described in the climate consultant software. The above design guidelines are classified according to envelope characteristics.

\section{Conclusion}

The following design guidelines have been concluded for the five cities, each representative of a particular zone:

1. The design guidelines extracted from the ASHRAE adaptive model (option 4) propose a totally different set of design guidelines in comparison to the CEC, ASHRAE 55 and ASHRAE 2005.

2. The adaptive model proposes guidelines for naturally ventilated buildings, so the natural cross ventilation and various other ways to encourage such design are of prime importance while designing climate responsive buildings. 
3. All the climate regions have found maximum possible similarities in design guidelines while using the option 4 of the adaptive model.

4. The use of the California model, ASHRAE 55 and 2005 propose a variety in guidelines as compared to the adaptive model for each region with respect to its climate settings.

The design guidelines and Passive design principles are common suggestive measures that can be applied to any house for the initial stage of design with the aim to reduce energy consumption and maximize the passive method application. The percentage saving of energy by the application of each guideline may vary because of its climate and situation dependency. That is why the validation of a particular design guideline should be further tested with the other software. But these passive measures can provide a beneficial start for initial design stages.

\section{Acknowledgement}

The research was supported by Higher Education Commission, Pakistan. The author acknowledges the contribution of Prof. Dr. Ing. Werner Lang (Technical University Munich, Germany) who provided his expertise and valuable comments for this research.

\section{References}

ADB (2009). Pakistan: Sustainable energy efficiency development program. <42051-PAK-TACR.pdf $>$. Islamabad, Pakistan.

ÇERÇİ, S. (2014). "CLIMATE RESPONSIVE RESIDENTIAL BUILDING DESIGN IN TURKEY-A CASE STUDY."

Enercon (1994). Pakistan solar architecture. Pakistan solar architecture (a selection of energy efficient house design). <solar.pdf>. Islamabad: 27.

Erickson, P. and K. Tempest (2014). "The contribution of urban-scale actions to ambitious climate targets." Stockholm Environment Institute-US Center, Davis, CA.

Givoni, B. (1992). "Comfort, climate analysis and building design guidelines." Energy and buildings 18(1): $11-23$.

Givoni, B. (1998). Climate considerations in building and urban design, John Wiley \& Sons.

HDIP (2013). Pakistan Energy Yearbook 2012. H. D. I. o. Pakistan. Islamabad, Pakistan, Hydrocarbon Development Institute of Pakistan, Ministry of petrolum and natural gas: 136.

Holdgate, M. W. (1987). "Changing habitats of the world." Oryx 21(3): 149-159.

Humphreys, M. A. (1975). Field studies of thermal comfort compared and applied, Building Research Establishment.

Khan, F. K. (1991). A geography of Pakistan: environment, people and economy, Oxford University Press.

Krishan, A. (2001). Climate responsive architecture: a design handbook for energy efficient buildings, Tata McGraw-Hill Education.

Lehmann, S. (2011). "Energy efficient building design: Towards climate responsive architecture." Sustainable built environment.

Millar, R. J., et al. (2017). "Emission budgets and pathways consistent with limiting warming to 1.5 C." Nature Geoscience 10(10): 741.

Milne, P. M. (2014). Climate consultant 6. California, University of California, Los Angeles.

Nicol, F. (2004). "Adaptive thermal comfort standards in the hot-humid tropics." Energy and buildings 36(7): 628-637.

Nicol, F. and S. Roaf (1996). "Pioneering new indoor temperature standards: the Pakistan project." Energy and buildings 23(3): 169-174. 
Nicol, J. F. and M. A. Humphreys (2002). "Adaptive thermal comfort and sustainable thermal standards for buildings." Energy and buildings 34(6): 563-572.

Nicol, J. F. and I. A. Raja (1997). "Indoor thermal comfort: the Pakistan study." Energy for Sustainable Development 3(5): 50-60.

Nicol, J. F., et al. (1999). "Climatic variations in comfortable temperatures: the Pakistan projects." Energy and buildings 30(3): 261-279.

Olgyay, V. (2015). Design with climate: bioclimatic approach to architectural regionalism, Princeton University Press.

Omer, A. M. (2008). "Energy, environment and sustainable development." Renewable and sustainable energy reviews 12(9): 2265-2300.

Parmesan, C. and G. Yohe (2003). "A globally coherent fingerprint of climate change impacts across natural systems." Nature 421(6918): 37.

Raja, I. A., et al. (1996). "Solar energy applications in Pakistan." Renewable energy 9(1): 1128-1131.

Shamshad, K. M. (1988). The meteorology of Pakistan: climate and weather of Pakistan, Royal Book Company Karachi,, Pakistan.

UN-Habitat, P. (2010). Energy efficient housing, Improvemnt of thermal performance of RC slab roofs. Islamabad, Pakistan: 69. 